\title{
Assessment of the Level of Technological Development in the Field of Research and Development: The Regional Dimension
}

\author{
Elena V. Berezina, Pavel P. Bochkovskiy, Konstantin V. Lebedev, Nadezhda A. Pluzhnova
}

\begin{abstract}
The purpose of this study is to examine the existing approaches to assessing the level of technological development of the countries of the world. Methods: Using the experience of previous studies, the article supports and develops ideas for constructing a composite index, allowing to assess the level of technological development of the research and development area at the subnational level. Results: According to the level of technological development of the sphere of research and development with the use of the proposed index, we compiled the rating of Russian regions. The factors, determining the gap in the level of technological development in the sphere of research and development, are identified, and the size of the existing gap between the Russian regions is estimated. In the course of the study, it was possible: to assess the level of technological development of research and development at the subnational level; to identify the strengths and weaknesses that affect the level of technological development of research and development; to identify Russian regions-leaders and regions-outsiders as a whole in terms of the level of technological development of the sphere of research and development, as well as for individual "referent elements"; to conduct a comparative analysis of the level of technological development in the sphere of research and development of Russian regions; to determine the impact of each subindex on the composite index. Practical relevance: The necessity of developing a given approach is substantiated simultaneously at the sectorial and regional levels. There is a composite index describing the level of technological development of research and development at the subnational level.

Keywords: scientific policy, technical policy, composite index, complex index, subindex, region.
\end{abstract}

\section{INTRODUCTION}

\section{A. Relevance of the study}

The need for scientific and technical policy is recognized by many countries of the world [3, 4, 19, 20,45]. Among the reasons for the increased attention to it we can distinguish:

Revised Manuscript Received on December 30, 2019.

* Correspondence Author

Elena Berezina*, Scientific Research Institute - Federal Research Centre for Projects Evaluation and Consulting Services (SRI FRCEC), Moscow, Russia.Email: e.berezina81@mail.ru

Pavel Bochkovskiy, Scientific Research Institute - Federal Research Centre for Projects Evaluation and Consulting Services (SRI FRCEC), Moscow, Russia. Email: pbochkovskiy@gmail.com

Konstantin Lebedev, Scientific Research Institute - Federal Research Centre for Projects Evaluation and Consulting Services (SRI FRCEC), Moscow, Russia. Email: kos.lebedev@gmail.com

Nadezhda Pluzhnova, , Scientific Research Institute - Federal Research Centre for Projects Evaluation and Consulting Services (SRI FRCEC), Moscow, Russia. Email: sonvik123@gmail.com

(C) The Authors. Published by Blue Eyes Intelligence Engineering and Sciences Publication (BEIESP). This is an open access article under the CC BY-NC-ND license (http://creativecommons.org/licenses/by-nc-nd/4.0/)
- degree and complexity of technologies, their interdependence,

- novelty of problems arising in the field of research,

- high speed of technological changes,

- unpredictable consequences of scientific discoveries [14 $15,23,25]$.

The formation of effective scientific and technical policy is impossible without a comprehensive analysis of the state and trends in the development of research and development, an integral part of which is the assessment of the level of technological development.

\section{B. Notion of the composite index}

The composite indexes are the one of the tools that allow us to assess the characteristics of complex processes, such as socioeconomic progress, globalization, innovative, technological development, etc. [27, 30-32, 44].

\section{Composite elements}

As composite elements of the composite index we define five "supporting elements":

- material and technical resources;

- human resources;

- cooperation of organizations in the implementation of research and development and the innovative activity of organizations;

- costs associated with research and development to create new and improve existing products and technological processes;

- release of innovative goods (works, services).

\section{Tendency for the use of indexes}

The growing tendency for the use of indexes for analysis and generalizations is explained by the fact that indeterminate qualitative characteristics are reduced to a clear, concrete and easily interpreted form [33, 34]. During the past two decades, various indexes have been proposed by individual researchers and international organizations [16, $17,36,37]$, some of which were used for cross-country level of comparison of technological development [12, 13, 42, 43]. At the same time, while choosing as the unit of analysis of the country as a whole, problems of intracountry differentiation remained outside of attention. The index calculated for the country, overstated the level of technological development for some of its regions and understated for others. The differences between regions could reach dozens of times.

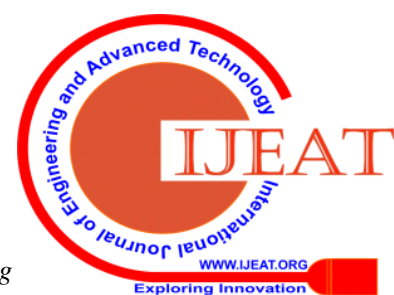


In recent years, researchers have been actively developing and applying indices to analyze complex processes, objects, or phenomena, allowing the identification of existing differences at both the subnational [5, 21, 22] and the municipal [1] levels.

\section{E. The purpose of this study}

Main purpose of this study is to propose an indicator that allows us to assess the level of technological development in the sphere of research and development at the subnational level. As an indicator, a composite index was made, using the example of Russian regions to identify interregional differences and determine their causes.

The construction of the index took into account the experience of previous studies on the nature of technological development and the measurement of this process.

\section{F. Main questions posed in the paper}

The paper poses two theoretical questions, the answers to which are of interest to the institutions responsible for the development of scientific and technical policy: the field of investigations and engineering at the subnational level, and what is its magnitude?

- The reasons for the differences in the level of technological development of research and development in the regions?

\section{G. Tasks that were solved}

When searching for answers to these questions, the following tasks were solved:

- the statistical information, which is necessary for building the index, is analyzed;

- the indicators for the final composite index are selected;

- the index values for the regions according to which they were reorganized, were calculated; regions was assessed and the factors influencing this gap were identified.

The results of the study were used in the summary report on the level of technological development of the economy of the Russian Federation on the whole and certain types of economic activity.

\section{LITERATURE REVIEW}

\section{A. The Index of Technological Progress}

One of the first comprehensive indicators assessing technological development is the Index of Technological Progress (ITP) [18]. This index characterized the achievements of the countries of the world in terms of the development of information technology. The index was calculated for 110 countries. At its construction five indicators were used:

- personal computers;

- Internet hosts;

- facsimile machines;

- mobile phones;

- TVs.

The index values ranged from 0 to 100 . The first ten places in the ranking of countries in the Technology Progress Index belonged to OECD member countries. The last ten positions were occupied by the countries of Sub-Saharan Africa.
- Is there a gap in the level of technological development of

- the gap in the level of technological development of the

\section{B. The Technology Achievement Index}

The United Nations Development Program (the United Nations Development Program) in the Human Development Report 2001 published the Technology Achievement Index (TAI) [39]. It was a complex indicator built on the basis of four subindexes:

- creation of technology;

- diffusion of recent innovations;

- diffusion of old innovations;

- human skills.

Each of the subindexes included two indicators. Both subindexes and their constituent indicators had equal weights. The index was calculated for 72 countries, which were divided into four groups:

- Leaders (TAI > 0.5);

- Potential leaders (TAI = 0.35-0.49);

- Actively introducing innovations (Dynamic adopters) (TAI = 0.35-0.49);

- Marginalized (TAI < 0.20).

\section{The ArCO Technology Index}

Using the principle of building the Technology Achievement Index, and improving it, Archibugi and Coco offered the Technology Capability Index for developed and developing countries (ArCo Technology Index) [10, 11]. The ArCo technology index, like the TAI index, was a complex indicator. It was built with three subindexes:

- the creation of technology;

- the technological infrastructures;

- the development of human skills.

The subindexes had equal weights. Unlike the Technology Achievement Index (TAI), the ArCO index allowed not only to conduct cross-country comparisons, but also comparisons in dynamics. The coverage of countries also increased. The index was calculated for 162 countries, which could be divided into four groups:

- leaders (from 1 to 25 place);

- potential leaders (from 26th to 50th place);

- latecomers (from 51 to 111 places);

- marginalized (from 112 to 162 places).

Between the isolated groups of countries there was a significant gap.

\section{The Technology Index}

In the Report on Global Competitiveness for 2001-2002, The World Economic Forum published the Growth Competitiveness Index. This index contained three subindexes, one of which was the Technology Index. Let us dwell on it in more detail. Initially, the Technology Index was calculated for 75 countries that were divided into two groups [24]. For the first group of countries (core economies), the Technology Index was formed taking into account two subindexes:

- Innovation Subindex;

- Subindex of information and telecommunication technologies (ICT Subindex).

The weight coefficients for them were equal. For the second group of countries (non-core economies), this index was built on three subindexes:

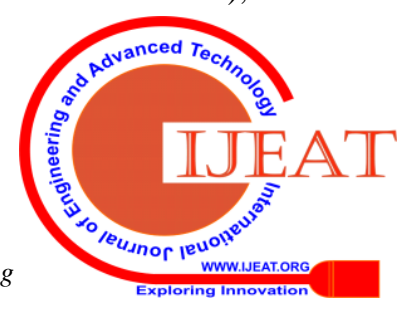


- Innovation Subindex (weight ratio 1/8);

- Subindex of information and telecommunication technologies (ICT Subindex) (weight coefficient 1/2);

- Technology Transfer Subindex (weight coefficient 3/8). In the future, the number of countries for which the index was calculated increased [2].

\section{E. The Technological Readiness Index}

In the Global Competitiveness Report for 2004-2005, The World Economic Forum presented a new index - the Global Competitiveness Index, it was a complex indicator. Initially, the Global Competitiveness Index was built on the basis of nine "pillars", which comprised three sub-indexes [28]. One of the "supporting elements" was the technological readiness (Technological Readiness), which characterizes the existing technological infrastructure of the country and the ability to apply domestic and foreign technologies.

In the future, the methodology for calculating the Global Competitiveness Index has been improved. Currently, his calculation is based on 12 "supporting elements" [26, 36, 37]. Increased coverage of countries for which the index is calculated.

\section{F. The Index of Industrial and Technological Advancement (ITA index)}

In 2005, the United Nations Industrial Development Organization (UNIDO) in its Report [27, 28, 40, 41] published the Index of Industrial and Technological Advancement (ITA index). This index was calculated on the basis of two subindexes:

- Industrial development subindex (Industrial advance);

- Subindex of technological development (Technological advance).

The subindex of technological development consisted of two indicators:

- the share of high- and medium-technology industries in industrial production;

- the share of exports of high- and medium-technology industries in the export of products.

The weight coefficients of these indicators were assumed to be equal.

\section{G. The Technological Activity Index}

Simultaneously with the Industrial and Technological Development Index, the United Nations Conference on Trade and Development (UNCTAD) presented the UNCTAD Innovation Capability Index (UNICI) [38]. The index consisted of two subindexes:

- the index of technological activity (the Technological Activity Index);

- the Human Capital Index.

Let us dwell on the first of them. Its components were three indicators:

- number of personnel performing research and development, per 1 million people of the population;

- number of patents granted to inventions by the United States Patent and Trademark Office (USPTO);

- number of scientific publications per 1 million people of the population.

These indicators had the same weighting coefficients. Subindex was calculated for 117 countries, which were Competitiveness Index (GCI) [29]. As the Growth

grouped into 4 groups:

- High innovation - 30 countries;

- Highly innovative medium level (Medium-high innovation) - 29 countries;

- Medium innovation - 29 countries;

- Low innovation - 29 countries.

\section{H. The Global Innovation Index (GII)}

Since 2007, the International Business School INSEAD, Cornell University and the World Intellectual Property Organization annually publish the Global Innovation Index (GII) [7-9].

This index is a complex indicator, calculated on the basis of two subindexes:

- resources needed to implement innovation (innovation inputs);

- results of innovation activities (innovation outputs).

The subindex "innovation inputs" is calculated on the basis of 5 "supporting elements" (institutions, infrastructure, human capital and research, the degree of development of the market and the degree of business development), and the subindex "innovation outputs" - based on two (products of knowledge, technology and creativity). In 2017, seven "supporting elements" included 81 indicators. The index was calculated for 127 countries, accounting for $92.5 \%$ of the world's population and $97.6 \%$ of the world's gross product $[6,9,36]$.

This review focuses on indices, which at different times were used to assess the level of technological development of countries. Many of them are not currently calculated.

\section{MATERIALS AND METHODS}

Using the experience of previous studies, the article supports and develops ideas for constructing a composite index, allowing to assess the level of technological development of the research and development area at the subnational level.

Two assumptions were made:

1. The scope of research and development has a certain specificity. As the results of research and development, not only material values (new materials, products, devices, systems, etc.) act, but also nonmaterial ones (new knowledge and concepts that may not initially have an applied nature).

In choosing a system of indicators characterizing the technological development of the sphere of research and development, the focus was on activities whose results are directly embodied in the form of innovative goods (works, services);

2. The concept of "region" can be used both in a broad and a narrower sense. In this study, the Russian federal districts acted as a region.

The construction of the composite index (Itd (r)) was based on the analysis of statistical information contained in Russian statistical databases. The analysis made it possible to distinguish five "supporting elements" that affect the technological development of the sphere of research and development:

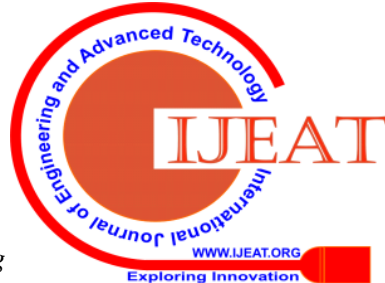


- material and technical base;

- human resources;

- level of cooperation of organizations in the implementation of research and development, innovative activity of organizations;

- costs associated with research and development to create new and improve existing products and processes;

- release of innovative goods (works, services).

These "supporting elements" contain 13 indicators. A comprehensive indicator of the level of technological development of the sphere of research and development of the region is calculated by the formula:

$$
I_{t d(r)}=\frac{I_{e q(r)}+I_{h r(r)}+I_{c(r)}+I_{e x(r)}+I_{i p(r)}}{5}
$$

where we have:

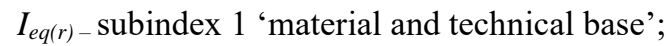

$I_{c(r)}$ - subindex 3 'cooperation of organizations and innovative activity';

$I_{e x(r)}$ - subindex 4 'costs associated with research and development to create new and improve existing products and processes';

$I_{i p(r)}$ - subindex 5 'release of innovative goods (works, services)'.

Each of the five subindexes has the same weight. It means that the composite index of technological development of the sphere of research and development of the region is the arithmetic mean of five subindexes.

The difference between the proposed index and similar ones is as follows. First, it is intended to be used simultaneously at the sectoral and subnational levels. Comparison at these levels gives an advantage in terms of the availability of statistical information. With cross-country comparisons, it is very often necessary to abandon certain indicators because of the unavailability of statistical data or their incompatibility. Hence the second difference, consisting in the collection of indicators of each of the "support elements".

Subindexes are calculated in the same way as the composite index. The weight coefficients of the indicators that make up the subindex are determined expertly.

The indicators, based on which the subindexes are calculated, are below:

- a1 - the share of machines and equipment under the age of 5 years in the total average annual cost of machinery and equipment in the field of research and development;

- a2 - the technician's level of researchers ${ }^{1}$;

- a3 - the cost of equipment included in the fixed assets, the average annual cost of machinery and equipment in the field of research and development;

- b1 - the proportion of researchers in the total number of personnel performing research and development;

\footnotetext{
${ }^{1}$ The technician's level of researchers is the average annual cost of machinery and equipment per researcher. Here and further we use the adjusted number of researchers (researchers in the field of social and human sciences are not taken into account).
}

$I_{h r(r)}$ - subindex 2 'human resources';

- b2 - the proportion of researchers with a degree (candidate, doctor of science) in the total number of researchers;

- b3 - the share of technicians in the total number of personnel performing research and development;

- b4 - the share of technicians with higher education in the total number of technicians;

- c1 - the proportion of organizations that carried out technological innovation in the total number of organizations surveyed in the field of research and development;

- c2 - the number of centers for the collective use of scientific equipment and unique scientific installations per one organization performing research and development;

- $\mathrm{d} 1$ - the share of domestic operating costs for research and development to create new and improve existing products and processes in the internal operating costs of research and development;

- $\mathrm{d} 2$ - the share of costs for technological innovations falling within the scope of research and development, in the total amount of costs for technological innovation in the economy as a whole;

- e1 - the share of innovative goods, works, services newly introduced or subjected to significant technological changes during the last three years in the total volume of innovative goods, works, services in the field of research and development;

- e2 - the share of innovative goods (works performed, services) in the total volume of goods shipped (work performed, services) by organizations in the field of research and development.

Instead of the actual values of the indicators for each of the regions, the normalized values calculated using the minimax normalization method:

$$
\frac{X_{i j(r)}-X_{\min (r)}}{X_{\max (r)}-X_{\min (r)}}
$$

where we have:

$\mathrm{X}_{\mathrm{ij}(\mathrm{r})}$ - the actual value of the $\mathrm{j}$-index of the region of the i-subindex;

$\mathrm{X}_{\min (\mathrm{r})}, \mathrm{X}_{\max (\mathrm{r})}-$ minimum and maximum values of the $j$ - index among the considered regions for the period of observation.

Below we have the formulas for calculating each of the five subindexes:

$$
\begin{gathered}
I_{\text {eq }(r)}=\sum_{j=1}^{3} a_{1(r)} * 0.4+a_{2(r)} * 0.3+a_{3(r)} * 0.3 \\
I_{h r(r)}=\sum_{j=1}^{4} b_{1(r)} * 0.5+b_{2(r)} * 0.3+b_{3(r)} * 0.1+b_{4(r)} * 0.1(4) \\
I_{c(r)}=\sum_{j=1}^{2} c_{1(r)} * 0.6+c_{2(r)} * 0.4 \\
I_{\text {ex }(r)}=\sum_{j=1}^{2} d_{1(r)} * 0.6+d_{2(r)} * 0.4 \\
\begin{array}{l}
\text { Published By: } \\
\text { Blue Eyes Intelligence Engineering } \\
\text { \& Sciences Publication }
\end{array}
\end{gathered}
$$




$$
I_{i p(r)}=\sum_{j=1}^{2} e_{1(r)} * 0.6+e_{2(r)} * 0.4
$$

\section{RESULTS}

The proposed approach was tested in assessing the level of technological development in the sphere of research and development in the Russian federal districts. The obtained values of the indices are presented in the Table 1.

Table 1. The values of subindexes and composite indexes for federal districts in 2013-2016

\begin{tabular}{|c|c|c|c|c|c|c|c|c|}
\hline $\begin{array}{l}\text { The values of subindexes and } \\
\text { composite indexes for federal districts } \\
\text { in 2013-2016 Federal district }\end{array}$ & \multicolumn{2}{|c|}{2013} & \multicolumn{2}{|c|}{2014} & \multicolumn{2}{|c|}{2015} & \multicolumn{2}{|c|}{2016} \\
\hline \multicolumn{9}{|c|}{ Composite index $-I_{t d(r)}$} \\
\hline Central & 0.51 & 5 & 0.53 & 4 & 0.61 & 2 & 0.58 & 3 \\
\hline Northwest & 0.57 & 2 & 0.57 & 2 & 0.59 & 4 & 0.59 & 2 \\
\hline South & 0.54 & 4 & 0.58 & 1 & 0.56 & 5 & 0.53 & 6 \\
\hline Volga & 0.57 & 3 & 0.53 & 5 & 0.68 & 1 & 0.60 & 1 \\
\hline Ural & 0.48 & 6 & 0.43 & 6 & 0.51 & 6 & 0.58 & 4 \\
\hline Siberia & 0.61 & 1 & 0.56 & 3 & 0.60 & 3 & 0.56 & 5 \\
\hline Far East & 0.33 & 7 & 0.36 & 8 & 0.36 & 8 & 0.33 & 7 \\
\hline \multicolumn{9}{|c|}{ Subindex $1-I_{e q(r)}$} \\
\hline & $\mathrm{I}_{\mathrm{eq}(\mathrm{r})}$ & Place & $\mathrm{I}_{\mathrm{eq}(\mathrm{r})}$ & Place & $\mathrm{I}_{\mathrm{eq}(\mathrm{r})}$ & Place & $\mathrm{I}_{\mathrm{eq}(\mathrm{r})}$ & Place \\
\hline Central & 0.16 & 8 & 0.23 & 8 & 0.43 & 6 & 0.33 & 6 \\
\hline Northwest & 0.41 & 7 & 0.37 & 7 & 0.48 & 4 & 0.34 & 5 \\
\hline North Caucasus & 0.47 & 5 & 0.60 & 3 & 0.43 & 7 & 0.51 & 2 \\
\hline Volga & 0.47 & 6 & 0.51 & 4 & 0.68 & 2 & 0.50 & 3 \\
\hline Ural & 0.69 & 1 & 0.66 & 2 & 0.75 & 1 & 0.69 & 1 \\
\hline Siberia & 0.69 & 2 & 0.43 & 5 & 0.52 & 3 & 0.29 & 7 \\
\hline Far East & 0.54 & 4 & 0.41 & 6 & 0.37 & 8 & 0.26 & 8 \\
\hline \multicolumn{9}{|c|}{ Subindex $2-I_{h r(r)}$} \\
\hline & $\mathrm{I}_{\mathrm{hr}(\mathrm{r})}$ & Place & $\mathrm{I}_{\mathrm{hr}(\mathrm{r})}$ & Place & $\mathrm{I}_{\mathrm{hr}(\mathrm{r})}$ & Place & $\mathrm{I}_{\mathrm{hr}(\mathrm{r})}$ & Place \\
\hline Central & 0.44 & 4 & 0.43 & 4 & 0.56 & 4 & 0.56 & 4 \\
\hline Northwest & 0.60 & 1 & 0.60 & 1 & 0.63 & 3 & 0.60 & 3 \\
\hline South & 0.26 & 6 & 0.38 & 5 & 0.47 & 5 & 0.43 & 6 \\
\hline North Caucasus & 0.35 & 5 & 0.32 & 6 & 0.34 & 8 & 0.32 & 8 \\
\hline Volga & 0.16 & 8 & 0.29 & 7 & 0.43 & 6 & 0.51 & 5 \\
\hline Ural & 0.23 & 7 & 0.23 & 8 & 0.42 & 7 & 0.42 & 7 \\
\hline Siberia & 0.55 & 2 & 0.59 & 2 & 0.73 & 1 & 0.75 & 1 \\
\hline Far East & 0.51 & 3 & 0.50 & 3 & 0.71 & 2 & 0.72 & 2 \\
\hline Central & 0.53 & 5 & 0.64 & 3 & 0.79 & 2 & 0.81 & 2 \\
\hline Northwest & 0.60 & 4 & 0.66 & 2 & 0.73 & 3 & 0.80 & 3 \\
\hline South & 0.65 & 2 & 0.41 & 5 & 0.50 & 5 & 0.59 & 4 \\
\hline North Caucasus & 0.19 & 8 & 0.27 & 7 & 0.22 & 8 & 0.25 & 8 \\
\hline Volga & 0.63 & 3 & 0.58 & 4 & 0.64 & 4 & 0.56 & 5 \\
\hline Ural & 0.31 & 6 & 0.08 & 8 & 0.25 & 7 & 0.43 & 7 \\
\hline Siberia & 0.81 & 1 & 0.71 & 1 & 0.93 & 1 & 0.88 & 1 \\
\hline Far East & 0.29 & 7 & 0.31 & 6 & 0.43 & 6 & 0.49 & 6 \\
\hline \multicolumn{9}{|c|}{ Subindex $4-I_{\text {ex }(r)}$} \\
\hline & $\mathrm{I}_{\mathrm{ex}(\mathrm{r})}$ & Place & $\mathrm{I}_{\mathrm{ex}(\mathrm{r})}$ & Place & $\mathrm{I}_{\mathrm{ex}(\mathrm{r})}$ & Place & $I_{e x(r)}$ & Place \\
\hline Central & 0.66 & 2 & 0.65 & 4 & 0.61 & 2 & 0.57 & 3 \\
\hline Northwest & 0.51 & 4 & 0.66 & 3 & 0.57 & 3 & 0.66 & 2 \\
\hline South & 0.38 & 6 & 0.44 & 6 & 0.43 & 6 & 0.22 & 6 \\
\hline North Caucasus & 0.03 & 7 & 0.02 & 7 & 0.11 & 7 & 0.06 & 7 \\
\hline Volga & 0.73 & 1 & 0.68 & 1 & 0.73 & 1 & 0.73 & 1 \\
\hline Ural & 0.43 & 5 & 0.51 & 5 & 0.51 & 4 & 0.57 & 4 \\
\hline Siberia & 0.59 & 3 & 0.68 & 2 & 0.45 & 5 & 0.50 & 5 \\
\hline Far East & 0.00 & 8 & 0.00 & 8 & 0.00 & 8 & 0.00 & 8 \\
\hline \multicolumn{9}{|c|}{ Subindex $5-I_{i p(r)}$} \\
\hline & $\mathrm{I}_{\mathrm{ip}(\mathrm{r})}$ & Place & $\mathrm{I}_{\mathrm{ip}(\mathrm{r})}$ & Place & $\mathrm{I}_{\mathrm{ip}(\mathrm{r})}$ & Place & $\mathrm{I}_{\mathrm{ip}(\mathrm{r})}$ & Place \\
\hline Central & 0.76 & 2 & 0.70 & 3 & 0.66 & 4 & 0.65 & 4 \\
\hline Northwest & 0.74 & 4 & 0.55 & 7 & 0.53 & 6 & 0.53 & 5 \\
\hline South & 0.74 & 5 & 0.91 & 1 & 0.92 & 1 & 0.97 & 1 \\
\hline North Caucasus & 0.53 & 6 & 0.81 & 2 & 0.78 & 3 & 0.40 & 6 \\
\hline Volga & 0.87 & 1 & 0.62 & 5 & 0.91 & 2 & 0.68 & 3 \\
\hline Ural & 0.75 & 3 & 0.68 & 4 & 0.63 & 5 & 0.80 & 2 \\
\hline
\end{tabular}




\begin{tabular}{|c|c|c|c|c|c|c|c|c|}
\hline Siberia & 0.40 & 7 & 0.40 & 8 & 0.36 & 7 & 0.40 & 7 \\
\hline Far East & 0.31 & 8 & 0.60 & 6 & 0.29 & 8 & 0.18 & 8 \\
\hline
\end{tabular}

The results of the research made it possible to identify the existing gap in the level of technological development of the sphere of research and development between the Russian federal districts and determine its magnitude. Between the first and last place in the rating gap was about 2 times:

- 1.97 times in 2013;

- 1.61 times in 2014;

- 1.89 times in 2015;

- 1.94 times in 2016.

Starting from 2014, this gap is widening.

In 2015 and 2016 years, on the level of technological development of the sphere of research and development the first place belonged to the Privolzhsky Federal District. In 2015, this federal district was in the lead in the rating of the subindex No. 4, in the subindex ratings No. 1 and No. 5 ranked second. In 2016, the Volga Federal District continued to lead in the rating of the subindex No. 4, but lost one position in the subindex ratings 1 and 5 .

The last two places in the level of technological development of the sphere of research and development belonged to the North Caucasus and Far Eastern Federal Districts. These federal districts in most cases occupied the last three places in the subindex ratings. The exception was subindex number 2 (in the rating of which the Far Eastern District was in the second and third positions, and the North Caucasus rose to the 5th) and the subindex number 1 (in the rating of which the North Caucasus District only dropped to 7th place, and only once The Far Eastern rose to the 4th).

Among the reasons that caused the differences in the level of technological development, we can distinguish the following:

- the state of the material and technical base necessary for research and development;

- the level of professionalism of personnel engaged in research and development;

- the degree of cooperation of organizations in the implementation of research and development, the level of their innovative activity;

- the amount of costs associated with creating new and improving existing products and technological processes, carrying out technological innovations.

\section{DISCUSSION}

The composite index proposed in this work for assessing the level of technological development of the sphere of research and development allowed:

- to assess the level of technological development of research and development at the subnational level;

- to identify the strengths and weaknesses that affect the level of technological development of the research and development area;

- to identify the regions-leaders and regions-outsiders as a whole in terms of the level of technological development of the sphere of research and development, and for individual "supporting elements";
- to conduct a comparative analysis of the level of technological development in the sphere of research and development of Russian regions;

- to determine the impact of each subindex on the composite index characterizing the level of technological development in the field of research and development.

At the same time, the study faced certain limitations:

- Presence of a subjective estimation at definition of weight factors of indicators on which subindexes are calculated. The most experienced expert a priori is not immune from error. Partially, this restriction is smoothed by averaging the weighting coefficients presented by the experts.

- Limited statistical information. Statistical observation covers not all organizations that implemented innovations. Individual organizations may not provide information for any reason.

- Lateness of statistical information. As a result, assessing the situation at the current time is very difficult or impossible.

- Availability of statistical information on individual indicators only from 2013.

\section{CONCLUSION}

Despite the existing limitations that were encountered during the study, it was possible to draw a picture of the level of technological development of the sphere of research and development of Russian regions. The results of the study were used in the summary report on the level of technological development of the economy of the Russian Federation as a whole and certain types of economic activity. In addition, the results obtained may be of interest to institutions responsible for the development of scientific and technical policy. As future directions of research, it is possible to suggest improving the presented approach to assessing the level of technological development of research and development at the subnational level.

\section{ACKNOWLEDGMENT}

The work was carried out at the Scientific Research Institute - Federal Research Centre for Projects Evaluation and Consulting Services with the financial support of the Ministry of Education and Science of the Russian Federation under terms of the State task for the project No. 26.12606.2018/12.1.

\section{REFERENCES}

1. A. S. Aladyshkina, L. A. Leonova, A. N. Krasnov, "Index of ecologica effectiveness for municipal management system: Possibilities and limitations", Ecology and Industry of Russia 21(1): 56-63, 2017. DOI 10.18412/1816-0395-2017-1-56-63 
2. J. Blanke, F. Paua, X. Sala-I-Martin, (2004). The Growth Competitiveness Index: Analyzing Key Underpinnings of Sustained Economic Growth. The Global Competitiveness Report 2003-2004. Oxford University Press. Retrieved from http://courses.wcupa.edu/rbove/eco343/030Compecon/general\%20co mpar/030900compet2.pdf

3. A. S. Soofi, "A comparative study of Chinese and Iranian Science and Technology, and techno-industrial development policies", Technological Forecasting and Social Change, 122: 107-118, 2017. DOI: 10.1016/j.techfore.2016.06.017

4. A. Tsvetkova, E. Katysheva, "Assessment of positive and negative aspects of CO2 sequestration projects by argument map development", 18th International Multidisciplinary Scientific Geoconference, SGEM 2018. Conference Proceedings, 18 (5.1). Ecology and Environmental protection. 2 July - 8 July, 2018. Albena, Bulgaria, 2018, pp. 75-80.

5. A. Xavier, M. D. B. Costa Freitas, R. Fragoso, M. D. S. Rosário, "A regional composite indicator for analysing agricultural sustainability in Portugal: A goal programming approach", Ecological Indicators 89: 84-100, 2018. DOI: 10.1016/j.ecolind.2018.01.048

6. L. M. Gokhberg, (sc. ed.). Innovation Rating development subjects Russian Federation. Moscow: High School of Economics, 2016. ISBN 978-5-7598-1508-2.

7. R. K. Nadirov, L. I. Syzdykova, A. K. Zhussupova, "Copper smelter slag treatment by ammonia solution: leaching process optimization", Journal of Central South University, 24: 2799-2804, 2017.

8. A. Strizhenok, D. Korelskiy. "Assessment of the state of soil-vegetation complexes exposed to powder-gas emissions of nonferrous metallurgy enterprises", Journal of Ecological Engineering, 17 (4): 25-29, 2016. DOI: 10.12911/22998993/64562

9. Cornell University, INSEAD and WIPO (2017). The Global Innovation Index 2017: Innovation Feeding the World, Ithaca, Fontainebleau, and Geneva. Retrieved http://www.wipo.int/edocs/pubdocs/en/wipo_pub_gii_2017.pdf

10. D. Archibugi, A. Coco, "A New Indicator of Technological Capabilities for Developed and Developing Countries (Arco)", CEIS Working Paper, 44, 2004. DOI: 10.2139/SSRN.487344

11. D. Archibugi, A. Coco, "Measuring technological capabilities at the country level: A survey and a menu for choice", Research Policy, 34 (2): 175-194, 2005. DOI: 10.1016/j.respol.2004.12.002

12. O. V., Savchina, O. V., Savchina, A. V. Asinovich, M. A. Kosyakov, A. L. Bobkov, "Energy sector of the Russian Federation in the context of macroeconomic instability", International Journal of Energy Economics and Policy, 7 (5): 28-33, 2017.

13. D. Archibugi, M. Denni, A. Filippetti, "The technological capabilities of nations: The state of the art of synthetic indicators", Technological Forecasting and Social Change 76 (7): 917-931, 2009. DOI: 10.1016/j.techfore.2009.01.002

14. O. F. Putikov, N. P. Senchina, I. V. Talovina, A. M. Duryagina, Y. M. Telegin, V. S. Nikiforova, "Geoelectrochemical detection of PGE content anomalies within the Svetlyi Bor massif (Central Urals)", Russian Geology and Geophysics, 58 (7): 1021-1028, 2017.

15. D. D. Stine, "Science and Technology Policymaking: A Primer", Congressional Research Service, (2009). Reprieved from https://fas.org/sgp/crs/misc/RL34454.pdf

16. D. Kiseláková, B. Šofranková, V. Čabinová, E. Onuferová, (2018). Competitiveness and sustainable growth analysis of the EU countries with the use of global indexes' methodology. Entrepreneurship and Sustainability Issues 5(3): 581-599. doi: 10.9770/jesi.2018.5.3(13).

17. D. Reckien, (2018). What is in an index? Construction method, data metric, and weighting scheme determine the outcome of composite social vulnerability indices in New York City. Regional Environmental Change 18(5): 1439-1451. doi: 10.1007/s10113-017-1273-7.

18. F. Rodríguez, E. J. III Wilson, (2000). Are Poor Countries Losing the Information Revolution? University of Maryland College Park. http://documents.worldbank.org/curated/en/600361468762019045/pdf /266510WP0Scode1tries0losing0Infodev.pdf.

19. G. Crespi, G. Dutrénit, (2014). Science, Technology and Innovation Policies for Development: The Latin American Experience. Springer International Publishing Switzerland. doi 10.1007/978-3-319-04108-7.

20. V. B. Kuskov, Ya. V. Kuskova, "Development of technology for the production of natural red iron oxide pigment", Inzynieria Mineralna (Mineral Engineering), 1 (39): 217-220, 2017.

21. J. A. García-Avilés, M. Carvajal-Prieto, A. De Lara-González, F. Arias-Robles, "Developing an Index of Media Innovation in a National Market: The case of Spain”, Journalism Studies 19(1): 25-42, 2018. DOI: 10.1080/1461670X.2016.1161496

22. J. Chen, J. Cheng, S. Dai, "Regional eco-innovation in China: An analysis of eco-innovation levels and influencing factors", Journal of Cleaner Production, 153: 1-14, 2017. DOI: 10.1016/j.jclepro.2017.03.141

23. J. J. Mulvihill, B. Capps, Y. Joly, T. Lysaght, H. A. E. Zwart, R. Chadwick, "Ethical issues of CRISPR technology and gene editing through the lens of solidarity", British Medical Bulletin 122 (1): 17-29, 2017. DOI: $10.1093 / \mathrm{bmb} / \mathrm{ldx} 002$

24. J. W. McArthur, J. D. Sachs, The Growth Competitiveness Index: Measuring Technological Advancement and the Stages of Development. The Global Competitiveness Report 2001-2002. Oxford University Press, 2001. Retrieved from http://earth.columbia.edu/sitefiles/file/Sachs\%20Writing/2002/World EconomicForum_2001-2002_GlobalCompetitivenessReport2001-200 2_GrowthCompetitivenessIndex.pdf

25. K. E. van Holde, J. Zlatanova, The Evolution of Molecular Biology: The Search for the Secrets of Life, 2018. DOI: 978-012812918-0

26. K. Schwab, X. Sala-i-Martín, "Global Competitiveness Report 2017-2018", World Economic Forum, 2017. Retrieved from http://www3.weforum.org/docs/GCR2017-2018/05FullReport/TheGlo balCompetitivenessReport2017\%E2\%80\%932018.pdf

27. M. Armiento, "The Sustainable Welfare Index: Towards a Threshold Effect for Italy", Ecological Economics, 152: 296-309, 2018. DOI: 10.1016/j.ecolecon.2018.06.014

28. M. E. Porter, K. Schwab, "Global Competitiveness Report 2006-2007", Palgrave MacMillan for the World Economic Forum, NY, 2006. Retrieved

from http://www3.weforum.org/docs/WEF_GlobalCompetitivenessReport_ 2006-07.pdf

29. M. E. Porter, K. Schwab, X. Sala-I-Martin, Global Competitiveness Report 2004-2005. Palgrave MacMillan, 2005. ISBN 978-1-4039-4913-4

30. M. Nardo, M. Saisana, A. Saltelli, S. Tarantola, "Tools for Composite Indicators Building”, European Communities, 2005. Retrieved from http://farmweb.jrc.cec.eu.int/ci/bibliography.htm

31. M. Szołtysek, S. Klüsener, R. Poniat, S. Gruber, "The Patriarchy Index: A New Measure of Gender and Generational Inequalities in the Past", Cross-Cultural Research, 51 (3): 228-262, 2017. DOI: $10.1177 / 1069397117697666$

32. O. V. Savchina, O. V. Savchina, A. L. Bobkov, A. Z. Sharashidze, "On the State of the Mortgage Market in the Russian Federation in the Conditions of Global Economic Crisis", Journal of Applied Economic Sciences, 11 (6(44)): 39-41, 2016.

33. OECD. Handbook on Constructing Composite Indicators. Methodology and User Guide. France, 2008. Retrieved from https://www.oecd.org/sdd/42495745.pdf

34. R. Nadirov, Y. Sabirov, "The New Approach to Enhance the Activity ofFe/N/C Catalyst for Oxygen Reduction Reaction by Electrochemical Treatment", Journal of New Materials for Electrochemical Systems, 21(2), 2018.

35. S. A. Ivanik, D. A. Ilyukhin, "Hydrometallurgical technology for gold recovery from refractory gold-bearing raw materials and the solution to problems of subsequent dehydration processes", Journal of Industrial Pollution Control, 2017. Retrieved from

http://www.icontrolpollution.com/articles/hydrometallurgical-technol ogy-for-gold-recovery-fromrefractory-goldbearing-raw-materials-and -the-solutionto-problems-of-subsequent-dehydration-processes-.php?a id $=85841$

36. S. G. Alekseev, N. P. Senchina, S. Y. Shatkevich. "Geoelectrochemical methods: Response to criticism and discussion of CHIM and MDI methods characteristics", 7th EAGE Saint Petersburg International Conference and Exhibition: Understanding the Harmony of the Earth's Resources Through Integration of Geosciences, 2016, pp. 229-233.

37. T. Dietz, J. Auffenberg, A. Estrella Chong, J. Grabs, B. Kilian, "The Voluntary Coffee Standard Index (VOCSI). Developing a Composite Index to Assess and Compare the Strength of Mainstream Voluntary Sustainability Standards in the Global Coffee Industry", Ecological Economics, 150: 72-87, 2018. DOI: 10.1016/j.ecolecon.2018.03.026

38. UNCTAD. World Investment Report. Transnational Corporations and the Internationalization of R\&D. UN Conference on Trade and Development. New York and Geneva, 2005. Retrieved from http://unctad.org/en/Docs/wir2005_en.pdf

39. UNDP. Human Development Report. Making new technologies work for human development. Oxford, NY, 2001. Retrieved from http://hdr.undp.org/sites/default/files/reports/262/hdr_2001_en.pdf

Published By:

Blue Eyes Intelligence Engineering

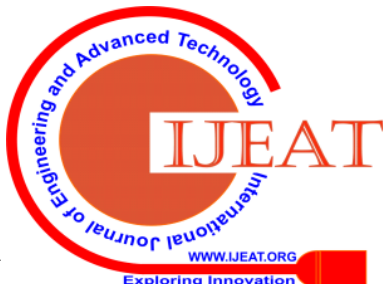




\section{Dimension}

40. UNIDO. Industrial development report. Capability Building for Catching-up: Historical, Empirical and Policy Dimensions, Vienna, $2005 . \quad$ Retrieved from https://ref.sabanciuniv.edu/sites/ref.sabanciuniv.edu/files/unido_indust rialdevelopmentreport_2005.pdf

41. V. B. Kuskov, Ya. V. Kuskova, "Research of physical and mechanical properties of briquettes, concentrated from loose high-grade iron ores", 17th International multidisciplinary scientific geoconference, SGEM 2017, 17: 1011-1015, 2017.

42. V. Jeremic, Z. Radojicic, M. Dobrota, "Emerging Trends in the Development and Application of Composite Indicators", IGI Global, 2016. DOI: $10.4018 / 978-1-5225-0714-7$

43. O. F. Putikov, N. P. Senchina, "Precise Solution of the System of Nonlinear Differential Equations in Partial Derivatives of the Theory of Geoelectrochemical Methods", Doklady Akademii Nauk (Doklady Earth Sciences), 2 (463): 726-727, 2015.

44. W. Becker, P. Paruolo, M. Saisana, A. Saltelli, "Weights and importance in composite indicators: Mind the gap", In: Springer Handbook of Uncertainty Quantification: 1187-1216, 2017. DOI: 10.1007/978-3-319-12385-1_40

45. Y. Zhao, C. Fautz, L. Hennen, K. Ravi Srinivas, Q. Li, "Public engagement in the governance of science and technology", In: L. Ladikas, Y. Zhao, S. Chaturvedi, D. Stemerding (eds.) Science and Technology Governance and Ethics: A Global Perspective from Europe, India and China: 39-51, 2015. DOI: 10.1007/978-3-319-14693-5_4 